\title{
Effects of varying length of stimulus series and response scale upon response latency, response uncertainty, and transmitted information'
}

\author{
LLOYd L, AYANT, WILLIAM BEVAN, AHD hILdA MNG \\ THE JOHNS HOPKINS UNIVERSITY
}

A 3 by 3 orthogonal design was employed to study the interrelations among response latency (RL), response uncertainty $\left(E_{R}\right)$, and transmitted information $\left(I_{t}\right)$. Nine groups of $S$ s judged the size of 5,20 , or 40 projected squares in terms of 5, 20, or 40 response categories. Patterns of change in $E_{R}$ and $R L$ over the three stimulus series were differentially effected by increases in the number of available response categories. The increase from 5 to 20 response categories produced, for successively longer stimulus series, a constantly increasing change in $\mathrm{E}_{R}$; the further increase from 20 to 40 categories produced a contrasting, constantly decreasing change in $E_{R}$. The same two changes in number of response categories produced the same pattern of change in $\mathrm{RL}$ over the 5-and 20-stimulus series but reversed the pattern for the 40-stimulus series. Correlations between $E_{R}$ and $\mathrm{RL}$ ranged from .28 to .99 and tended to maximize when number of response categories equaled the number of stimuli. $I_{t}$ was relatively low under all conditions. Within the 5- and 20-stimulus series, increases from 5 to 20 to 40 available responses increased $R L$ in a negatively accelerated fashion but did not increase $\mathrm{I}_{t}$. Within the 40-stimulus series, the same increases in number of available responses produced an essentially linear increase in both $\mathrm{I}_{t}$ and $\mathrm{RL}$.

Psychologists have displayed a long-term interest in the reaction time experiment as a means of studying psychophysical relationships and of relating properties of stimuli to their attendant response systems (e.g., Cattell, 1902; Johnson, 1939; Cartwright, 1941; Saltzman \& Garner, 1948; Bricker, 1955). Recently, Behar (1963) investigated the relation of number of available response categories to both reaction time and judgment. When ss used either 2 or 10 response categories for judging the size of a series of 10 stimuli, response latency (RL) and uncertainty of category judgment ( $\left.E_{11}\right)$ were highly correlated (.91 and .85). Furthermore, because the ratio of response latencies for the two judgmental conditions (3.46) so nearly matched the ratio of response uncertainties (3.32), Behar suggested $R T$ as a convenient substitute for $E_{R}$. Parametrically exploring the relationship suggested by Behar, Bevan and Avant (1968) asked Ss to judge 10 stimuli in terms of $2,4,8,16,32$, or 64 categories, and they reported correlation coefficients ranging from .82 to .90 .
For each of the conditions of their experiment, Bevan and Avant also computed, for each S, a measure of transmitted information $\left(\mathrm{I}_{\mathrm{t}}\right)$ corrected for statistical bias (Carleton, 1968). Consistent with the earlier observations of Hake and Garner (1951) and Eriksen and Hake (1955) with uncorrected It measures, they reported an increase in $I_{t}$ with increases in the number of available categories. This relationship reached its asymptote when number of response categories approximated the number of stimuli to be judged. Further additions to the number of available response categories had no appreciable effect upon $I_{t}$. In fact, a slight decline in $I_{t}$ with the most extensive scale (64 categories) suggested that a reliable decrease in the $I_{t}$ function would accompany further increases in the ratio of number of response categories to the number of judged stimuli.

In the present experiment the ratio of number of stimuli to number of responses was varied from 1:8 to $8: 1$ in order to test further the limits of the relationships just described.

\section{Subjects}

\section{METHOD}

Subjects were nine 10-member groups of male undergraduates at Towson State College, Towson, Maryland. The experimental design orthogonally included 5-, 20-, and 40-member stimulus series and 5-, 20-, and 40 -category response scales as the independent variables.

Materials

The three stimulus series consisted of projected photographs of 5,20 , or 40 dark gray squares. When projected, stimuli of the 40 -member series varied, in increments of 1 in., from 1 to $40 \mathrm{in.} \mathrm{on} \mathrm{a} \mathrm{side.}$ The 20- and 5-member series consisted, respectively, of numbers 11-30 and 18-22 of the 40-member series.

\section{Procedure}

A Kodak Carousel slide projector was used to project each stimulus series. The $S$ initiated each trial by pressing a switch, simultaneously effecting projection of the appropriate slide and starting a Standard electric clock. The $\mathrm{E}$ terminated each trial and stopped the clock by pressing a second switch when he heard the second word of S's 'ategory judgment. Response latencies were read to $.01 \mathrm{sec}$. The click of $E$ 's resetting the clock served as $S$ 's cue to initiate 
the next trial. A Hunter Model 111-C interval timer, wired to the clock, kept it running until E responded. An opaque screen separated S and E.

After each $\mathrm{S}$ had been instructed that the experiment dealt with reaction time and size judgment, he was shown how to project the stimuli. The use of category scales was then explained and his attention was directed to a response scale attached to the wall immediately to the right of the projection screen. This scale was a vertical line divided into 5,20 , or 40 categories, with the top and bottom labeled, respectively, "large" and "small." Category divisions were marked with two-digit numbers, and $S$ was requested to express his judgments in these terms. This response nomenclature, like that of the Bevan and Avant study, was devised to minimize the differential effect of the physical process of vocalization upon response times. The 5 -category scale ranged from 64 to 68 . The medium of the 20- and 40-category scales was between 65 and 66 , and the extremes were, respectively, at 56 and 75 and at 46 and 85 .

With no practice trials and no instructions regarding the "correct" assignment of stimuli to categories, each $S$ gave 160 responses to several randomlyordered stimulus sequences: 4 to each of 40 stimuli, 8 to each of 20 stimuli, or 32 to each of 5 stimuli. Both response latency and category judgment were recorded by $E$ prior to resetting the clock on each trial. $E_{R}$ and $I_{t}$ were calculated for each $S$ in the usual manner. An estimate of the bias in each measure was then calculated for each of the nine experimental conditions by Carleton's (1968) procedure, with each estimate based upon a cumulative matrix computed from the responses of the $10 \mathrm{Ss}$ in each experimental group.

\section{RESULTS AND DISCUSSIOH}

$E_{R}$, number of stimuli, and number of response categories

Average $E_{R}$ and average $R L$ for each series of stimuli are separately plotted in the two panels of Fig. 1. Both measures were independently evaluated for each stimulus series, and summaries of these analyses are presented in Table 1.

For the 5- and 20-stimulus series, the same conclusions were prompted by analyses of the $\mathrm{E}_{\mathrm{R}}$ measure (Table 1). In both series, response uncertainty was reliably higher for middle than for end stimuli; in addition, response uncertainty (i.e., inconsistency) increased with each addition to the number of available judgmental categories. However, increases in the number of response categories did not differentially affect uncertainty of response to individual stimuli.

When the stimulus series included 40 squares, not only did uncertainty of response differ among stimuli and among response scales, but the difference in response uncertainty between middle and end stimuli was enhanced with increases in the length of the response scale.

\section{$\mathbf{R L}$, number of stimuli, and number of response categories}

The latency data plotted in Fig. 1b revealed patterns quite like those observed in the uncertainty measure. With the 5- and 20-member series, response latency was greater for middle than for end stimuli, and mean

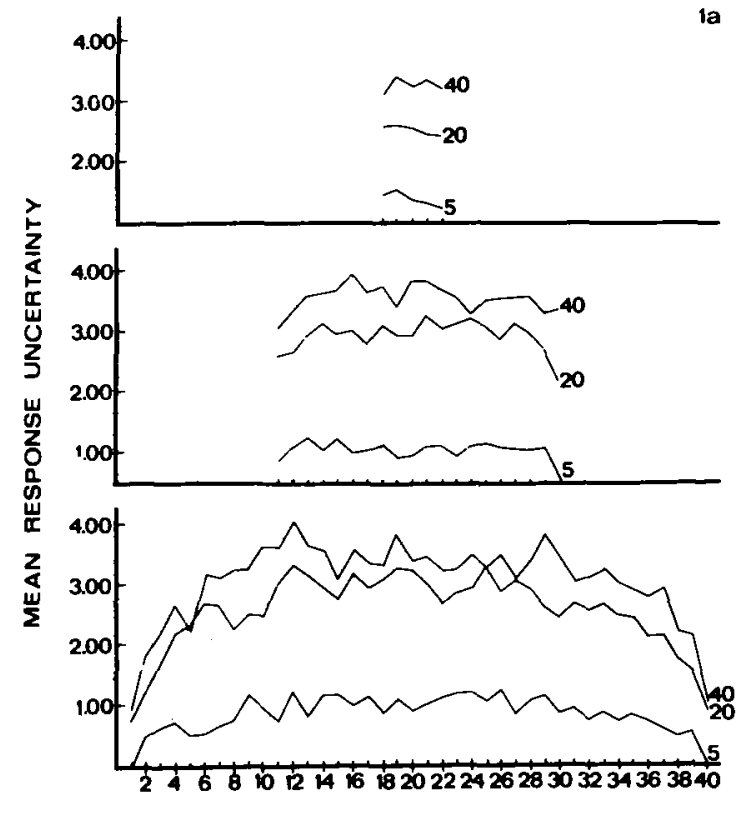

STIMULI

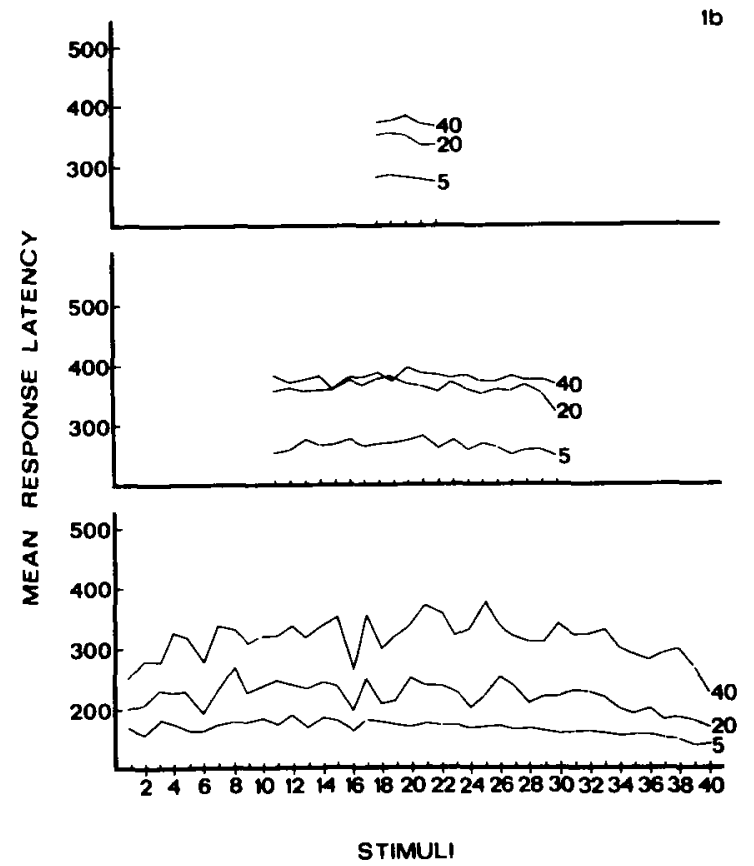

Fig. 1. Mean response uncertainty and mean response Iatency for individual stimuli when the stimulus series consisted of 5,20 , or 40 members. The several curves represent results when the response scale included 5 , 20 , or 40 response categories. Fig. 1a presents the uncertainty measure in bits, and Fig. lb the latency data in msec. 
Table 1. F Ratios from the Analyses of Variance of the $E_{R}$ and $R I$. Data

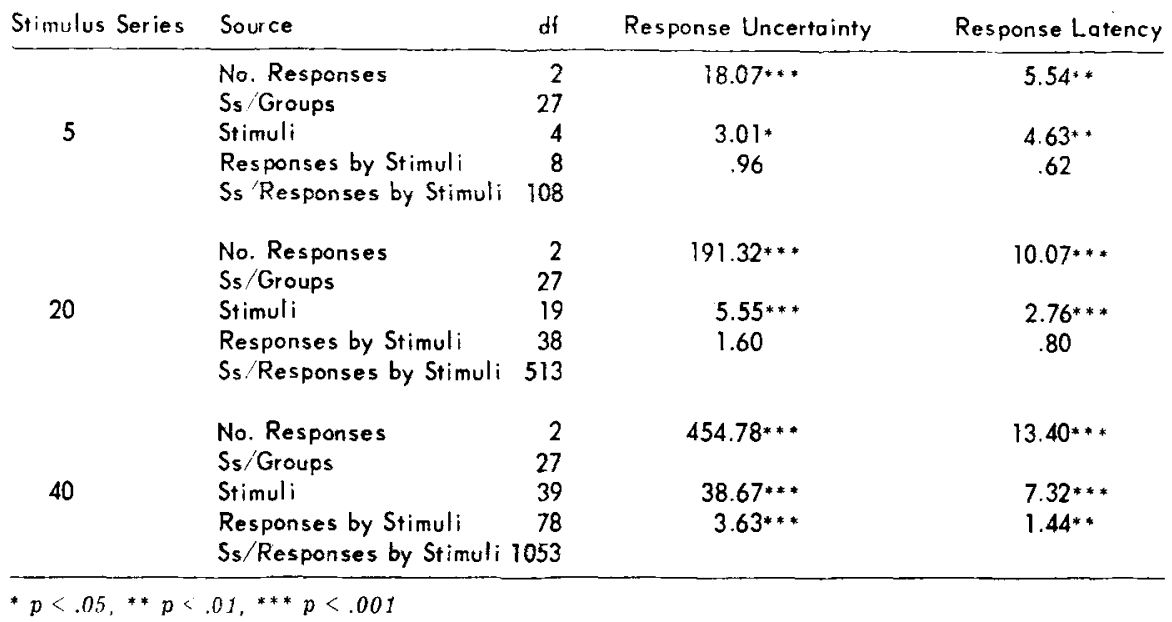

latency increased with additions to the number of available response categories, but number of available categories did not differentially influence response times for different stimuli. Finally, when 40 stimuli were presented for judgment, responses to stimuli in the middle of the series were significantly longer than to stimuli at the ends, and they were lengthened by longer response scales. In contrast to the 5- and 20-member series, the difference in response latency to the middle and extremes of the 40-stimulus series was enhanced as categories were added to the response scale.

As noted above, the differential effect of longer response scales on middle and end stimuli failed significance in the $E_{R}$ and RL measures for the 5and 20-stimulus series. However, the $R L$ and $\mathbf{E}_{\mathbf{R}}$ curves for these series (Fig. 1) indicate progressively clearer trends toward the symmetrical shape and the significantly enhanced difference in effect of longer response scales on individual stimuli which appear in the curves for the 40-stimulus series. Similarly shaped RL functions have been reported by Jones and Parducci (1967) who used squares in a geometric progression of widths. The symmetrical shape of the present functions, and their resemblance to those reported by Jones and Parducci, indicate that the progressive decrease in proportional change in stimulus size with a constant linear increment did not systematically influence discriminability among series members. Such observations are important because the concern of the present experiment is with predominantly judgmental processes unconfounded by differential discriminability among judged stimuli.

\section{Pattems of change in $E_{R}$ and $R L$.}

Compared aeross respective stimulus series, the patterns of percentage change in $E_{R}$ and $R L$ as response categories were added imply limiting quali- fications for Behar's (1963) conclusion that RL may substitute for $E_{R}$. Table 2 summarizes these changes. The increase from 5 to 20 response categories produced, for successively longer stimulus series, a constantly increasing change in $E_{R}$; in contrast, the further increase from 20 to 40 categories produced a constantly decreasing change. In the case of the latency measure, the two successive increases in number of available categories produced, for the 5and 20-stimulus series, increasing and then decreasing changes which paralleled the $E_{\mathbf{R}}$ functions. However, when 40 stimuli were to be judged, the two increases in response scale length reversed the trend of change in RL. Thus, in line with Behar's suggestion, the representative $S$ became increasingly uncertain in his category judgment of 5 or 20 stimuli as more response categories were made available, and this uncertainty was reflected, in similar fashion, in the time required to make the judgments. However, with the more demanding task of judging 40 stimuli, the initial increase in number of response categories produced similar increases in the two measures, while the increase to 40 categories lessened further increase in $E_{R}$ and exaggerated further increase in RL. This finding implies a limited range of task difficulty within which RL may effectively substitute for $E_{R}$.

Table 2. Percent Increases in $F_{R}$ and $R L$ Acnss Stimulus Series with Increases from 5 to 20 and from 20 to 40 Response Categories Increases in No.

\begin{tabular}{llrrr} 
of Categories & Measure & \multicolumn{2}{c}{ Length of Stimulus Series } \\
\hline \multirow{3}{*}{5 to 20} & $\mathrm{E}_{\mathrm{R}}$ & $\mathbf{5}$ & 20 & $\frac{40}{19}$ \\
& $\mathrm{RL}$ & 23 & 185 & 198 \\
20 to 40 & $\mathrm{E}_{\mathrm{R}}$ & 28 & 32 & 20 \\
& $\mathrm{RL}$ & 8 & 21 & 20 \\
& & & 5 & 32
\end{tabular}




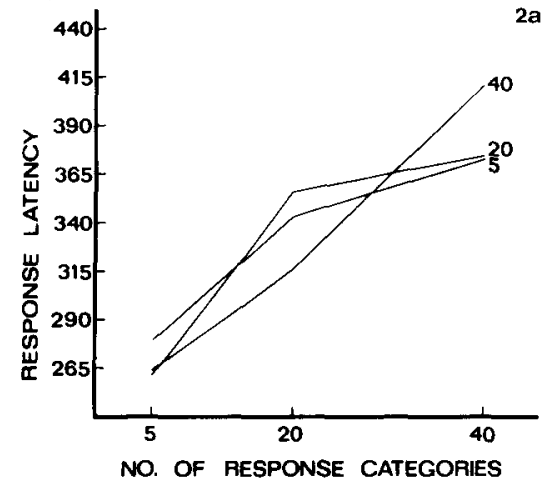

\section{The correlation between $E_{R}$ and $R L$}

A second indication of the limitations of Behar's substitutability hypothesis for $R L$ and $E_{R}$ is found in the pattern of correlation coefficients obtained from the present data. For the 5-member stimulus series, Pearson r's for 5-, 20-, and 40-category scales were, respectively, $.92, .99$, and .31 . For the 20-stimulus series, corresponding $\mathrm{r}$ 's were $.45, .61$, and .28 , and for the 40-stimulus series, $r$ 's for the respective response scales were $.56, .50$, and .66 . These values show relatively little relationship between $E_{R}$ and RL when number of judgmental categories markedly exceeded number of stimuli. The trend apparent in these values is toward the highest level of relationship when stimulus series and response scale are of equal length. The clarity of this state of affairs is diminished by the discrepant pattern of r's obtained with the 5-stimulus series and the fact that, while the Bevan and Avant data revealed the same, though less marked, trend through the six conditions of that experiment, Behar reported the reverse pattern of coefficients for the two conditions of his experiment. The reasons for these discrepant results are at present unclear and require further investigation.

\section{$R L$ and $I_{t}$}

Figure 2 presents mean response latency and average information transmitted for each condition of the experiment. As in the earlier reports by Bricker (1955), Behar (1963), and Bevan and Avant (1968), average response latency for each stimulus series increased reliably with each increase in number of available response categories (Table 1). For the 5- and 20stimulus series, this increase in RL was accompanied by a low level of information transmission, with $\mathrm{I}_{t}$ as high for 5 as for 20 or 40 response categories (5 Stimuli $-F_{G \text { roups }}=1.68, \mathrm{df}=2 / 27, \mathrm{p}>.05 ; 20$ Stimuli $-F$ Groups $=3.05, d f=2 / 27, p>.05$ ). However, while in the 40-stimulus series overall level of information transmission remained low, an essentially linear increase in RL with changes from 5 to 20 to 40 categories was accompanied by a similar increase in transmitted information (40 Stimuli $-\mathrm{F}_{\mathrm{Groups}}=34.88, \mathrm{df}=2 / 27$, $p<.001)$.

The finding that with the 5-stimulus series ratios of response categories to judged stimuli as high as 4:1 and 8:1 produced a zero slope transmission function, when coupled with the earlier results of Hake and Garner (1951) and Eriksen and Hake (1955), casts doubt on Bevan and Avant's (1968) suggestion that noise is added to the transmission system when response categories markedly exceed the number of stimuli to be judged. Meanwhile, some ambiguity in the interpretation of the present transmission functions results from the fact that, with the 40 -stimulus series, transmission reliably increased with each addition to the number of available categories while, with the 20-stimulus series, the level of transmission was twice that of the 5-stimulus series but transmission was no better with 20 or 40 categories than with 5 .

\section{References}

Behar, I. On the relation between response uncertainty and reaction time in category judgment. Percept. mot. Skills, 1963, 16, 595596.

Bevan, W, \& Avant, L. L. Response latency, response uncertainty, information transmitted, and the number of available judgmental categories. J. exp. Psychol., 1968, 76, 394-397.

Bricker, P. D. The identification of redundant stimulus patterns. J. exp. Psychol., 1955, 49,73-81.

Carleton, A. G. On the bias of information estimates. Psychol. Bull., 1968. Submitted for review.

Cartwright, D. Relation of decision-time to the categories of response, Amer. J. Psychol., 1941, 54, 174-196.

Cattell, J. Mck. The time of perception as a measure of difference in intensity. Philos. Stud., 1902, 19, 63-68.

Eriksen, C. W., \& Hake, H. W. Absolute judgment as a function of stimulus range and number of stimulus and response categories. J. exp. Psychol., 1955, 49, 323-332.

Hake, H. W. \& Garner, W. R. The effect of presenting various numbers of discrete steps on scale reading accuracy. $J$. exp. Psychol., 1951, 42, 358-366.

Johnson, D. M. Confidence and speed in the two-category judgment. Arch. Psychol., New York, 1939, No. 241.

Jones, L. E., \& Parducci, A. Stimulus uncertainty and the latency of category judgment. Psychon. Sci., 1967, 7, 71-72.

Saltzman, I. J., \& Gamer, W. R. Reaction time as a measure of span of attention. $J$. Psychol, , 1948, 25, 227-241.

\section{Note}

1. This work was performed under Contract N00014-67-A-0 163-00 between the Physiological Psychology Branch, Office of Naval Research, and The Johns Hopkins University.

(Accepted for publication February 14, 1968.) 